\title{
Neuroprotective effect of magnesium on lipid peroxidation and axonal function after experimental spinal cord injury
}

\author{
$\mathrm{T}_{\text {Süzer*, }}{ }^{1}, \mathrm{E}_{\text {Coskun }}{ }^{1}, \mathrm{H}$ Islekel $^{2}$ and $\mathrm{K}$ Tahta $^{1}$ \\ ${ }^{1}$ Department of Neurosurgery, Pamukkale University School of Medicine, Denizli, Turkey; ${ }^{2}$ Department of \\ Biochemistry, Dokuz Eylül University School of Medicine, Izmir, Turkey
}

\begin{abstract}
Study design: An experimental study examining the neuroprotective effect of magnesium on axonal function and lipid peroxidation in a rat model of acute traumatic spinal cord injury. Objective: To determine the effectiveness of postinjury treatment with magnesium on evoked potentials and lipid peroxidation after spinal cord injury (SCI).

Setting: Pamukkale University, Denizli, Turkey.

Methods: Spinal cord injury occurred in 30 rats with an aneurysm clip at T9 and the rats were randomly assigned to undergo subcutaneous administration of one of the following at $1 \mathrm{~h}$ after injury: (1) Physiological saline $(n=10)$; (2) $\mathrm{MgSO}_{4}, 300 \mathrm{mg} / \mathrm{kg}(n=10)$ and (3) $\mathrm{MgSO}_{4}, 600 \mathrm{mg} / \mathrm{kg}(n=10)$. Spinal somatosensory evoked potentials (SSEPs) were recorded before injury, 30 min after injury and $3 \mathrm{~h}$ after injections. Rats were killed $24 \mathrm{~h}$ after the injury, and malondialdehyde (MDA) levels were measured.

Results: Following SCI, there were significant decreases in the amplitudes of P1 and N1 $(P<0.001)$ and only high-dose magnesium improved the SSEPs $(P<0.01)$. On the other hand, there was significant difference in lipid peroxide content between high-dose magnesium treated group and both of saline treated and low-dose magnesium treated groups $(P<0.01)$.

Conclusion: These results suggest that magnesium has a dose-dependent neuroprotective effect on SSEPs and lipid peroxidation after experimental spinal cord injury.
\end{abstract}

Keywords: spinal cord injury; lipid peroxidation; magnesium; evoked potentials

\section{Introduction}

The pathophysiology of spinal cord injury is complex and has not been fully elucidated. ${ }^{1}$ There is evidence that progressive pathophysiological changes occur at the level of trauma, resulting in a reduction in spinal cord blood flow and a decrease in the tissue oxygen levels and all these lead to ischemia and the subsequent second injury. ${ }^{2-7}$ Moreover, release or activation of autodestructive factors causes to lipid peroxidation and calcium-mediated cellular toxicity. 8,9 It is believed that these mechanisms are interactive. $1,10,11$

Much evidence implicates the influx of calcium ions via the $N$-methyl-D-aspartate (NMDA) receptor complex in pathogenesis of ischemic injury and cell death. ${ }^{12,13}$ A variety of pharmacological agents designed to prevent NMDA receptor activation or to modify the cascade of events that follow this activation have been synthesized.

Magnesium is a readily available, inexpensive NMDA receptor antagonist with a well established clinical profile in obstetrical and cardiovascular practice. ${ }^{14,15}$ Magnesium ions play an important role in neuronal cellular physiology by competing with

*Correspondence: T Süzer, Department of Neurosurgery, Pamukkale University, School of Medicine, P.K. 66, Denizli, TR-20100, Turkey calcium ions, acting as an endogenous calcium channel blocker and gating NMDA receptor-associated ion channels. ${ }^{16}$ Moreover, magnesium is essential for normal cell functions such as membrane integrity, cellular respiration, transcription by messenger RNA, protein synthesis, glucose and energy metabolism, and regulation and $\mathrm{Ca}^{2+}$ transport and accumulation. ${ }^{17-20}$ Feldman et $a l^{21}$ have reported that, postinjury treatment with $\mathrm{Mg}^{2+}$ attenuated brain edema formation and improved neurological outcome after experimental head trauma in rats. On the basis of these data, we conducted the present study to determine the efficacy of magnesium as a neuroprotective agent in a rat model of spinal cord injury.

\section{Materials and methods}

\section{Surgical procedure}

Our experimental protocol was approved by the Animal Care and Use Committee of Pamukkale University. Thirty adult male albino rats, weighing between 210 and $310 \mathrm{~g}$ were used for the experiments. Animals were anesthetized by an intraperitoneal injection of ketamine $(50 \mathrm{mg} / \mathrm{kg})$ and xylazine $(9 \mathrm{mg} /$ 
$\mathrm{kg}$ ). The right femoral artery and vein were cannulated. Lactated Ringers solution was administered intravenously to maintain hydration. The arterial line was used to monitor heart rate and blood pressure, and to assess arterial blood gases. During surgical procedures, body temperature was maintained between 37 and $38^{\circ} \mathrm{C}$ with a water-filled heating pad. The spinal cord was exposed by a bilateral laminectomy of T9. All animals were subjected to an extradural clip compression of the cord at T9 with an aneurysm clip (Yasargil, FE 691K, Aesculap AG, Germany) exerting a force of $50 \mathrm{~g}$ for $30 \mathrm{~s}$, an injury which caused paraplegia.

\section{Evoked potentials}

It was previously reported that the spinal somatosensory evoked potentials were not influenced by anesthetic levels of ketamine unlike cortical somatosensory evoked potentials, so that we used spinal somatosensory evoked potentials (SSEPs) to monitor axonal function. ${ }^{22}$ The SSEPs were obtained with a Medelec Premiere Plus (Medelec Ltd., UK) prior to injury and at $30 \mathrm{~min}$ and $4 \mathrm{~h}$ after the injury. The recording electrodes were inserted percutaneously just lateral to spinous process of the T2, so that the tips rested on the laminae. To record the SSEPs, left sciatic nerve was stimulated by bipolar electrodes with square wave pulses of $0.1 \mathrm{~ms}$ duration and $5 \mathrm{~mA}$ intensity delivered at $5 \mathrm{~Hz}$. The filter range was $3 \mathrm{~Hz}$ to $3 \mathrm{kHz}$. Sixty-four responses were averaged and displayed. The SSEPs recorded before and after the spinal cord injury were compared by measuring the latency and amplitude of each component wave.

\section{Experimental protocol}

Following the preinjury SSEP recordings, all animals were subjected to a spinal cord compression injury at T9 with a $50 \mathrm{~g}$ aneurysm clip for $30 \mathrm{~s}$. The SSEPs were recorded at $30 \mathrm{~min}$ after injury. After these recordings, the rats were randomly assigned to subcutaneous injection of either (1) physiological saline, $(n=10)$; (2) $\mathrm{MgSO}_{4}, 300 \mathrm{mg} / \mathrm{kg}(n=10)$ or (3) $\mathrm{MgSO}_{4}, 600 \mathrm{mg} / \mathrm{kg}$ $(n=10)$. Posttreatment SSEP recordings were obtained at $3 \mathrm{~h}$ after injections. When the animals awakened from anesthesia after the study, they were returned to their cages and the bladders were compressed manually every $6 \mathrm{~h}$.

\section{Estimation of lipid peroxide}

All the animals were killed by intracardiac injection of $\mathrm{KCl} 24 \mathrm{~h}$ after trauma, and the T9 spinal cord segment was removed quickly (within $30 \mathrm{~s}$ ) and immediately frozen with liquid nitrogen. Tissues were homogenised in ice-cold $\mathrm{KCl}(1.5 \% \mathrm{w} / \mathrm{v})$ to make a $10 \%$ homogenate (w/v) using a glass Teflon homogeniser. Lipid peroxide was estimated according to the method of Rehncrona et $a l .^{23}$ Aliquots of spinal cord homogenates were extracted with $0.5 \mathrm{ml}$ of trichloroacetic acid $(20 \%$ $\mathrm{w} / \mathrm{v})$. After centrifugation for $10 \mathrm{~min}$ at $3000 \mathrm{rpm}$, $0.9 \mathrm{ml}$ supernatant was added to $1.0 \mathrm{ml}$ of thiobarbituric acid $(0.67 \% \mathrm{w} / \mathrm{v})$ dissolved in $0.26 \mathrm{M}$ Tris- $\mathrm{HCl}$ buffer. The samples were heated in boiling water for $10 \mathrm{~min}$. After cooling, the absorbance was recorded at $532 \mathrm{~nm}$. The amounts of lipid peroxides were calculated as thiobarbituric acid reactive substances (TBARS) and tetraethoxypropane was used as standard. The content of TBARS was calculated by comparison with the standard curve, and the level of lipid peroxides was expressed as nanomoles per gram of wet tissue.

\section{Statistical analysis}

All data were evaluated in a blinded fashion and expressed as the mean \pm SD. SPSS statistics package (SPSS Inc., Chicago, IL, USA) was used for all statistical processing. Statistical comparisons were performed using analysis of variance (ANOVA), Tukey's honestly significant difference (HSD) test, paired $t$-test and Wilcoxon matched-pairs signed-ranks test. Probability values less than 0.05 were considered statistically significant.

\section{Results}

\section{Evoked potentials}

Representative preinjury, postinjury and posttreatment SSEP recordings are illustrated in Figure 1. ANOVA and Tukey's HSD test revealed no significant differences in the amplitudes of both $\mathrm{P} 1$ and N1 among the three treatment groups before the injury. The amplitudes of SSEPs were decreased significantly at $30 \mathrm{~min}$ after the injury in all 30 animals (paired $t$ test, $P<0.001)$. Moreover, Wilcoxon matched-pairs signed-ranks test revealed significant differences be-

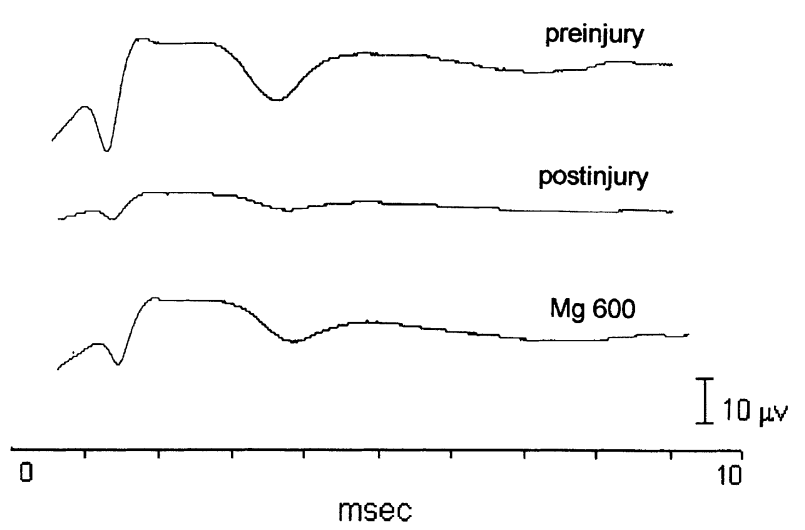

Figure 1 Representative SSEP recordings before and $30 \mathrm{~min}$ after the spinal cord injury, and $3 \mathrm{~h}$ after the administration of $\mathrm{MgSO}_{4}(600 \mathrm{mg} / \mathrm{kg})$. The amplitudes of SSEPs were significantly attenuated at $30 \mathrm{~min}$ after spinal cord injury. There was significant improvement in the amplitudes of SSEPs in the high-dose $(600 \mathrm{mg} / \mathrm{kg})$ magnesium treated animals 
tween the postinjury and preinjury amplitudes of P1 $(P<0.01)$ and N1 $(P<0.01)$ for all groups. The reduction in the $\mathrm{N} 1$ and $\mathrm{P} 1$ amplitudes did not recover in the saline treated $(P>0.05)$ and low-dose magnesium treated $(P>0.05)$ groups. In the high-dose magnesium treated groups, there was significant
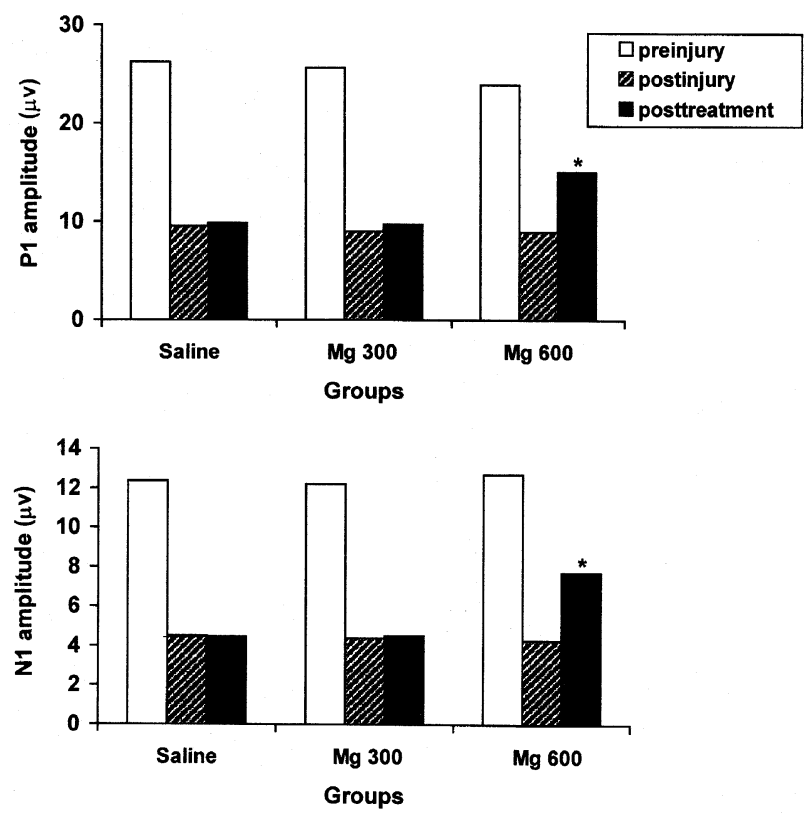

Figure 2 Bar graphs showing the amplitudes of P1 (upper) and N1 (lower) in each experimental group ( $n=10$ per group). The animals were treated $1 \mathrm{~h}$ after spinal cord injury with saline, $300 \mathrm{mg} / \mathrm{kg}(\mathrm{Mg} 300)$ or $600 \mathrm{mg} / \mathrm{kg} \quad(\mathrm{Mg} 600)$ $\mathrm{MgSO}_{4}$. The amplitudes of $\mathrm{P} 1$ and $\mathrm{N} 1$ were significantly recovered in the high-dose $\mathrm{Mg}$ treated group when compared with postinjury measurements $(* P<0.01)$

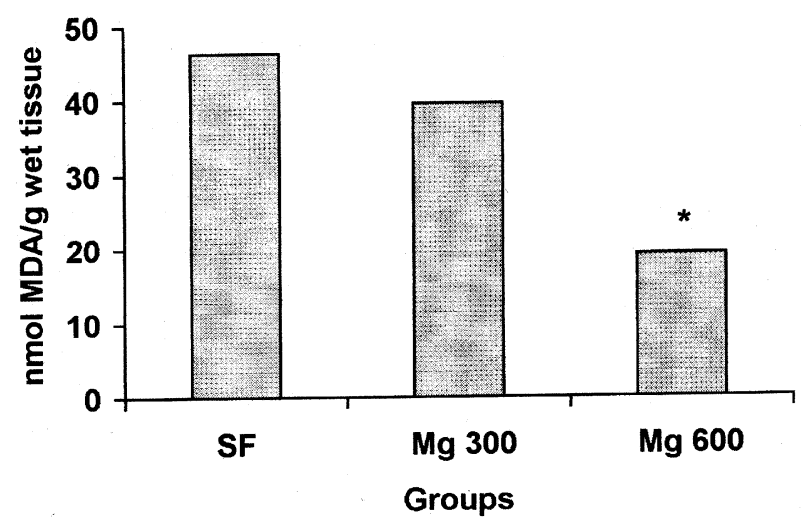

Figure 3 Bar graphs showing the MDA contents in each treatment group. MDA content was found to be lower in the high-dose magnesium treated group when compared with saline treated and low-dose magnesium treated groups $\left({ }^{*} P<0.01\right)$. The difference between saline treated and lowdose magnesium treated groups was statistically insignificant $(P<0.05)$ improvement in the amplitudes of P1 $(P<0.01)$ and N1 $(P<0.01)$ when compared with postinjury measurements (Figure 2).

\section{Biochemistry studies}

MDA contents in each treatment group were shown in Figure 3. The difference between saline treated and low-dose magnesium treated groups was statistically insignificant $(P>0.05)$. The MDA content was found to be lower in the high-dose magnesium treated group than in the saline treated and low-dose magnesium treated groups $(P<0.01)$.

\section{Discussion}

It has been reported that spinal cord injury is caused by direct and indirect mechanisms. ${ }^{7,24,25}$ The pathological lesion in the spinal cord injury requires $1-2 \mathrm{~h}$ to develop. $^{24,26}$ This lag time is necessary to allow a delayed injury process. Secondary injury processes include ischemia, release of excitotoxic neurotransmitters, free radical generation, lipid peroxidation, and influx of calcium ions in to the neurons.

Neuroprotective effects of high-dose methylpredinsolone, opiate receptor antagonists, and calcium channel antagonists on spinal cord injury have been reported. Methylprednisolone suppresses the breakdown of membranes by inhibiting lipid peroxidation and hydrolysis at the site of injury. ${ }^{27-29}$ Since Faden et $a l^{30}$ reported that opiate system play a major role in the pathophysiology of spinal cord injury, opiate receptor antagonist naloxane has been widely used in the treatment of spinal cord injury. ${ }^{31-33}$ Calcium antagonists have been shown to increase blood flow in the brain and spinal cord, and decrease cellular toxicity; thus, they have been extensively studied in spinal cord trauma. $1,7,33,35$

Neuroprotective effects of magnesium has been shown in experimental models of permanent focal cerebral ischemia, transient global ischemia, spinal cord ischemia, traumatic brain injury, topically induced quinolinate hippocampal neurodegeneration, perinatal postasphyxial brain damage, and delayed cerebral vasospasm after subarachnoidal haemorrhage. ${ }^{12,36-38}$ Marinov et $a l^{12}$ have shown the beneficial effect of magnesium in rats subjected to transient focal cerebral ischemia, and suggested that the neuroprotective effect of magnesium was dose dependent and could be documented by improved neurological outcome, decreased volume of infarct, and diminished histological evidence of neuronal injury in the ischemic border zone. McIntosh et $a l^{37}$ have studied the effect of magnesium after traumatic brain injury in rats, and postulated that postinjury treatment with magnesium was effective in limiting the extent of neurological motor dysfunction. Ram et al ${ }^{38}$ have shown the beneficial effect of magnesium sulfate in the treatment of subarachnoidal haemorrhageinduced vasospasm in rat. Feria et $a l^{39}$ have reported 
an almost complete suppression of autonomy in rats deafferented by sciatic and saphenous neurectomy 30 min after being injected with magnesium sulfate.

It has been shown that magnesium ions play an important role in neuronal cellular physiology by competing with calcium ions, acting as endogenous calcium channel blocker and gating NMDA receptorassociated ion channels. Moreover, magnesium is essential for a number of cellular processes, including glycolysis, oxidative phosphorylation, protein synthesis DNA and RNA aggregation, and the maintenance of plasma membrane integrity. Neuroprotective mechanism of magnesium include inhibition of excitatory neurotransmitter release, blockage of calcium channels and blockage of the NMDA-glutamate receptor.

This is the first study correlating the decrease of lipid peroxidation measured by MDA levels and improvement of axonal function assessed by SSEP caused by magnesium treatment in spinal cord injury. Our study provided quantitative evidence demonstrating that high-dose $(600 \mathrm{mg} / \mathrm{kg})$ magnesium significantly attenuates the increase in MDA levels observed after spinal cord injury. Magnesium treatment used in this study was also shown to improve axonal function assessed by evoked potentials. Low-dose $(300 \mathrm{mg} / \mathrm{kg})$ magnesium, however, was not effective.

Hall and Braughler ${ }^{6}$ reported that cell membrane damage after spinal cord injury might be induced by free-radical reaction and lipid peroxidation. Experiments have shown that the free-radical-initiated peroxidative procedure occurs in the injured spinal cord. $^{4,6,8,11,24,29,40}$ In this study, tissue lipid peroxidation was evaluated by measuring the thiobarbituric acid reactive substances (TBARS). ${ }^{23}$ MDA, formed from the breakdown of polyunsaturated fatty acids, serves as a convenient index for determining the extent of lipid peroxidation. MDA is also a well known secondary product of lipid peroxidation in spinal myelin, glial, and neuronal membranes. ${ }^{24,41}$ The results of our study demonstrated that MDA levels in the high-dose $\mathrm{MgSO}_{4}$ treated group were significantly lower than the saline treated group and the lowdose $\mathrm{MgSO}_{4}$ treated group (Figure 3).

It is known that there is still controversy regarding the values of evoked potentials for assessing the electrophysiological integrity of the spinal cord after SCI. Ross and Tator ${ }^{1}$ reported that their experiment failed to demonstrate an improvement in electrophysiological function in any rat at any time after SCI. Nacimiento et $a l^{42}$ concluded that SSEP changes in cats did not reflect the severity of acute SCI. However, several studies in rats using clip compression injury have demonstrated beneficial effects on evoked potentials after drug treatments. ${ }^{7,35,43}$ To check the lesion severity and evoked potential responses, we performed a preliminary study using the same aneurysm clip $(50 \mathrm{~g})$ for $1 \mathrm{~min}$ compression injury, and we were not able to analyse the amplitudes because of the large number of absent responses; thus the compression time was chosen to be $30 \mathrm{~s}$. In our study, decline in the amplitudes if SSEPs occurred after clip compression significantly improved in highdose magnesium treated group. However, the decreased amplitudes did not recover in saline treated and low-dose magnesium treated groups.

The present study demonstrated that postinjury treatment with magnesium after traumatic spinal cord injury attenuated lipid peroxidation and improved axonal function. One possible mechanism for its beneficial effect is the blockage of the calcium channels and NMDA-glutamate receptor; magnesium blocks NMDA receptor-ion channel in the brain and spinal cord. ${ }^{16,21} \mathrm{~A}$ second possible mechanism is the essential role of magnesium for a number of cellular processes, including regulation of calcium transport, glycolysis, protein synthesis, and the maintenance of plasma membrane integrity. ${ }^{17,18,37}$ In addition, it is known that a fall in intracellular free and total magnesium occurs following traumatic injury and $\mathrm{Mg}$ deficiency exacerbates posttraumatic neurologic dysfunction; treatment with $\mathrm{Mg}$ prevents the fall in intracellular free magnesium. ${ }^{19,37}$

Our study did not reveal the underlying mechanisms by which the improvement by magnesium was brought out. Further efforts should be made to explore these mechanisms in more detail and to develop optimum treatment strategies.

In summary, the results of this study indicate a significant beneficial effect of magnesium in rats subjected to spinal cord injury. The neuroprotection was dose-dependent and could be documented by improved electrophysiological function and decreased lipid peroxidation. Further work is needed to evaluate the routes, dosages and conditions with which the administration of magnesium could be valuable for the neuroprotection in spinal cord injury.

\section{References}

1 Ross IB, Tator CH. Spinal cord blood flow and evoked potential responses after treatment with nimodipine or methylprednisolone in spinal cord-injured rats. Neurosurgery 1993; 33: 470-477.

2 Flamm ES et al. Experimental spinal cord injury: treatment with naloxone. Neurosurgery 1982; 10: $227-231$.

3 Akdemir $\mathrm{H}$ et al. Histopathology of experimental spinal cord trauma. Res Exp Med, 1992; 192: 177-183.

4 Koc RK et al. Effect of methylprednisolone, tirilazad mesylate and vitamin $\mathrm{E}$ on lipid peroxidation after experimental spinal cord injury. Spinal Cord 1999; 37: 29-32.

5 Collins WF. A review and update of experimental and clinical studies of spinal cord injury. Paraplegia, 1983; 21: 204-219.

6 Hall ED, Braughler JM. Effects of intravenous methylprednisolone on spinal cord lipid peroxidation and $\mathrm{Na}^{2+}-\mathrm{K}^{+}$ATPase activity: dose response analysis during 1 st hour after contusion injury in the cat. $J$ Neurosurg 1982; 57: 247-253.

7 Fehlings MG, Tator $\mathrm{CH}$, Linden RD. The effect of nimodipine and dextran on axonal function and blood flow following experimental spinal cord injury. $J$ Neurosurg 1989; 71: 403-416.

8 Koc RK et al. Lipid peroxidation in experimental spinal cord injury. Res Exp Medl 1995; 195: 117-123.

9 Braughler JM, Hall ED. Effects of multi-dose methylprednisolone sodium succinate administration on injured cat spinal cord neurofilament degeneration and energy metabolism. J Neurosurg, 1984; 61: $290-295$. 
10 Halt PS, Swanson RA, Faden AI. Alcohol exacerbates behavioral and neurochemical effects of rat spinal cord trauma. Arch Neurol 1992; 49: 1178-1184.

11 Braughler JM, Duncan LA, Chase RL. Interaction of lipid peroxidation and calcium in the pathogenesis of neuronal injury. Cent Nerv Syst Trauma 1985; 2: 269-283.

12 Marinov MB et al. Neuroprotective effects of preischemia intraarterial magnesium sulfate in reversible focal cerebral ischemia. J Neurosurg 1996; 85: $117-124$.

13 Lipton SA, Rosenberg PA. Excitatory amino acids as a fina common pathway for neurologic disorders. $N$ Engl J Med 1994; 330: $613-622$.

14 McLean RM. Magnesium and its therapeutical uses: a review. Am J Med 1994; 96: 63-76.

15 Belfort MA, Moise Jr KJ. Effects of magnesium sulfate on maternal brain blood flow in preeclampsia: a randomized placebo-controlled study. Am J Obstet Gynecol 1992; 167: 661 666.

16 Nowak L, Bregestovski P, Ascher P. Magnesium gates glutamate-activated channels in mouse central neurones. Nature 1984; 307: $462-465$

17 Garfinkel L, Garfinkel D. Magnesium regulation of the glycolytic pathway and the enzymes involved. Magnesium 1985; 4: 60-72.

18 Ebel H, Günther T. Magnesium metabolism: a review. J Clin Chem Clin Biochem 1980; 18: 257 - 270.

19 Vink et al. Decline in intracellular free $\mathrm{Mg}^{2+}$ is associated with irreversible tissue injury after brain trauma. J Biol Chem 1988 263: $757-761$.

20 Kass IS, Cottrell JE, Chambers G. Magnesium and cobalt, not nimodipine, protect neurons against anoxic damage in the rat hyppocampal slice. Anesthesiology 1988; 69: 710-715.

21 Feldman $\mathrm{Z}$ et al. Effect of magnesium given 1 hour after head trauma on brain edema and neurological outcome. J Neurosurg 1996; 85: $131-137$

22 Giulian D, Robertson C. Inhibition of mononuclear phagocytes reduces ischemic injury in the spinal cord. Ann Neurol 1990; 27: $33-42$.

23 Rehncrona S et al. Peroxidative changes in brain cortical fatty acids and phospholipids, as characterized during $\mathrm{Fe}^{2+}$ and ascorbic acid stimulated peroxidation in vitro. $J$ Neurochem 1980; 34: $1630-1638$.

24 Ildan $\mathrm{F}$ et al. Effects of naloxone on sodium- and potassiumactivated and magnesium dependent adenosine-5' - triphosphase activity and lipid peroxidation and early ultrastructural findings after experimental spinal cord injury. Neurosurgery 1995; 36: $797-805$.

25 Ducker TB, Kindt GW, Kempe LG. Pathological findings in acute experimental spinal cord trauma. J Neurosurg 1971; 35: $700-798$.

26 Nelson E et al. Spinal cord injury: The role of vascular damage in the pathogenesis of central hemorrhagic necrosis. Arch Neurol 1977; 34: $332-333$
27 Hall ED, Wolf DL, Braughler JM. Effects of a single large dose of methylprednisolone sodium succinate on experimental posttraumatic spinal cord ischemia. Dose-response and time-action analysis. J Neurosurg 1984; 61: 124-130.

28 Hall ED. Neuroprotective pharmacology of methylpredinsolone. J Neurosurg 1992; 76: 23-31.

29 Young W, Flamm ES. Effect of high-dose corticosteroid therapy on blood flow, evoked potentials, and extracellular calcium in experimental spinal cord injury. J Neurosurg 1982; 57: $667-673$.

30 Faden AI, Jacobs TP, Holaday JW. Endorphins in experimental spinal injury: therapeutic effect of naloxone. Ann Neurol 1981; 10: $326-332$

31 Black et al. Naloxone and experimental spinal cord injury: Part IHigh dose administration in a static load compression model. Neurosurgery 1986; 19: 905 -908.

32 Flamm ES et al. Experimental spinal cord injury treatment with naloxone. Neurosurgery 1982; 10: 227-231.

33 Young W et al. Effect of naloxone on post-traumatic ischemia in experimental spinal contusion. J Neurosurg 1981; 55: 209-219.

34 Guha A, Tator CH, Piper I. Effect of a calcium channel blocker on posttraumatic spinal cord blood flow. J Neurosurg 1987; 66: $423-430$.

35 Imamura $\mathrm{H}$, Tator $\mathrm{CH}$. Effect of intrathecal nimodipine on spinal cord blood flow and evoked potentials in the normal or injured cord. Spinal Cord 1998; 36: 497-506.

36 Izumi Y, Poussel S, Pinard E, Seylaz J. Reduction of infract volume by magnesium after middle cerebral artery occlusion in rats. J Cereb Blood Flow Metab 1991; 11: 1025-1030.

37 McIntosh TK, Vink R, Yamakami I, Faden AI. Magnesium protects against neurological deficit after brain injury. Brain Res, 1989; 482: $252-260$.

38 Ram Z et al. Magnesium sulfate reverses experimental delayed cerebral vasospasm after subarachnoid hemorrhage in rats. Stroke, 1991; 22: $922-927$.

39 Feria M, Abad F, Sanchez A, Abreu P. Magnesium sulphate injected subcutaneously suppresses autonomy in peripherally deafferented rats. Pain 1993; 53: $287-293$.

40 Tuzgen $\mathrm{S}$ et al. The effect of epidural cooling on lipid peroxidation after experimental spinal cord injury. Spinal Cord 1998; 36: $654-657$.

41 Wallace $\mathrm{MC}$, Tator $\mathrm{CH}$. Failure of blood transfusion or naloxone to improve clinical recovery after experimental spinal cord injury. Neurosurgery 1986; 19: 489-494.

42 Nacimiento AC, Bartels M, Loew F. Acute changes in somatosensory evoked potentials following graded experimental spinal cord compression. Surg Neurol 1986; 25: 62-66.

43 Guha A, Tator CH, Smith CR, Piper I. Improvement in posttraumatic spinal cord blood flow with a combination of calcium channel blocker and a vasopressor. J Trauma 1989; 29: $1440-1447$. 